\title{
Modelling the swimming response of late stage larval reef fish to different stimuli
}

\author{
Paul R. Armsworth* \\ School of Mathematics and Physics, James Cook University, Townsville, Queensland 4811, Australia
}

\begin{abstract}
This paper examines the importance of directed motion towards reefs by late stage larval reef fish for determining recruitment rates to substrate-associated adult populations. The significance of reliance on different sensory faculties for orientation, and of different larval swimming and sensory capabilities, is explored with mathematical models. A 4-way classification is examined, separating weak and strong swimming larvae, and larvae relying on current-dependent and -independent cues for orientation. The relative importance of factors determining supply rates varies among these 4 cases, but, in general, purely hydrodynamically based considerations of incidental recruitment, or passive entrainment in re-circulatory features around reefs, appear less important than considerations of larval swimming, and the interaction of swimming with these physical transport processes. The extent of sensory capabilities of larvae proves to be a critical parameter, and the rate of larval supply depends sensitively upon it, for species relying on both current-dependent and -independent cues. The consequences of these findings are discussed, with particular reference to the potential for active behaviour to influence settlement patterns of different species.
\end{abstract}

KEY WORDS: Coral reef fish - Pelagic larvae - Directed motion - Swimming capabilities - Sensory faculty $\cdot$ Larval supply rate

\section{INTRODUCTION}

\section{General background}

Most reef fishes have a dispersing larval stage, which ends when the larvae leave the pelagic environment and recruit into substrate-associated adult populations. The supply rate of larvae to reefs for recruitment is believed to be a critical determinant of the structure of reef fish populations (Doherty \& Williams 1988, Doherty \& Fowler 1994). The importance of supply considerations is acknowledged by those managing reef fisheries and other industries exploiting these populations (James et al. 1990, Russ 1991, Dayton et al. 1995, Done et al. 1997).

The dispersal paths of pelagic larvae are determined in part by advection in the hydrodynamic regime around

\footnotetext{
- Present address: Department of Biological Sciences, Stanford University, Stanford, California 94305-5020, USA.

E-mail: armsworth@leland.stanford.edu
}

reefs. Environmental stochasticity (James et al. 1997) and inherent system sensitivities in the hydrodynamics (Ridderinkhof \& Zimmerman 1992, Sanderson et al. 1995) imply that large variations in any 'source-sink' relationships should be expected. While supply considerations may have important management implications, making informed decisions based on limited predictions of noisy, uncertain supply data will be difficult.

Recent evidence has suggested that some late stage larval fish have substantial swimming and sensory capabilities, which could allow them to influence their dispersal and subsequent recruitment (Stobutzki \& Bellwood 1994, 1997, Leis et al. 1996, Leis \& CarsonEwart 1997). The ability to swim in these young fish larvae may be a significant departure in evolutionary and ecological respects from larvae of marine invertebrates. While evidence has shown that reef fish larvae have the capability to affect their dispersal, determining if, and how, they utilise these capabilities is a challenge fraught with logistical difficulties (Leis 1991, Leis et al. 1996). Subsequent attempts at un- 
derstanding dispersal and recruitment relationships should consider these potentially significant locomotory capabilities (Bellwood et al. 1998).

One conclusion that could be drawn from this initial discussion is that the added complexity of having to consider the independent locomotory capabilities of larvae when studying dispersal and recruitment increases the difficulty in obtaining the data needed for informed management. However, an alternative, more optimistic view, and a view motivating this current work, is that if pelagic larvae behave in some predictable manner then their ability to influence their dispersal could act to smooth over environmental variability. Therefore, while behavioural considerations make dispersal questions harder to answer, they could provide a mechanism for ensuring that those questions are answerable at all.

\section{Larval capabilities}

Late stage larval reef fish of some species possess substantial swimming capabilities. Individuals have been observed in the laboratory to attain non-burst swimming speeds greater than those of ambient currents, and to sustain speeds comparable with the currents for a period of several days without rest (Stobutzki \& Bellwood 1994, 1997). These observations have been supported by in situ measurements of the swimming speeds of released larvae (Leis \& CarsonEwart 1997). Larvae could use these independent locamotory capabilities to influence their pelagic dispersal, and one hypothesis is that they use them to migrate towards reefs from open water prior to settlement (Wolanski et al. 1997).

Larvae need to be able to orientate themselves to utilise their swimming capabilities for directed motion. Data obtained by Leis et al. (1996) from field observations indicate that some late stage larvae can detect the location of a reef from over $1 \mathrm{~km}$ away. While the majority of released larvae were observed to swim away from the reef, this could be attributed to the fact that observations were made during daytime, a time thought to be unfavourable for settlement success (Dufour \& Galzin 1993, Leis et al. 1996, Leis \& CarsonEwart 1998). Nocturnal experiments have detected a significant on-shore movement of late stage larvae (Doherty \& Mcllwain 1996, Stobutzki \& Bellwood 1998). Possible sensory cues that larvae could use to detect the presence of reefs are discussed by Leis et al. (1996), who suggest a classification into 2 groupings, separating larvae that rely on current-dependent and current-independent mechanisms.

The observations of Leis et al. (1996) and Stobutzki \& Bellwood (1998) suggest that the cue used for reef detection is current-independent, because results were consistent across study sites on both upstream and downstream sides of the reef. Indirect supporting evidence suggesting a current-independent cue comes from observations that Iarvae appear to orient towards reefs while still upstream (Wolanski et al. 1997).

One possible current-independent cue is sound. Direct evidence of larvae using sound for orientation is lacking, but measurements indicating that noise levels around reefs are substantially higher than background levels are at least suggestive (McCauley \& Cato 1998).

While a reliance on current-dependent mechanisms appears to be inconsistent with the observations of Leis et al. (1996) and Stobutzki \& Bellwood (1998), supporting evidence for such mechanisms can be found in the literature. It is known that certain species can detect gradients in concentration of chemical signals released from interspecific and conspecific organisms on the reef (Sweatman 1988, Elliot et al. 1995, Arvedlund \& Nielsen 1996). Doherty et al. (1996) raise the possibility that reef fish larvae could orient along temperature gradients formed when shallow water over reefs is warmed and plumes downstream. A third possibility is that the distortions to the current field due to blocking by reefs (Wolanski \& Hamner 1988) stimulate some rheotactic response from larvae.

There is no reason to expect that larvae will rely upon just 1 sensory faculty during the transition from pelagic to benthic environments. A more likely conclusion would be that the choice of sensory mechanisms utilised will reflect the diversity of requirements larvae must meet to settle successfully. A larva could then draw upon a set of sensory faculties, and orient with respect to a corresponding set of signals and cues. For example, it could be found that visual cues aid in microhabitat choice once on the reef, but audial cues are used to orient to that reef in the first place. Such scale-driven variation in sense dependence is suspected to operate in other fish species (Dittman \& Quinn 1996). We should also not expect larvae of different species to rely upon the same sets of sensory cues, and when considering different species we should expect the set of faculties to change.

\section{Significance of larval locomotion}

Early models that assumed larvae were advected passively during the dispersal and recruitment process predicted a large proportion of propagules would be lost from reef systems (Dight et al. 1990a,b). Kingsford et al. (1991) and Dight \& Black (1991) proposed that recirculatory features in the lee of reefs could entrap dispersing larvae, and thereby increase the effective reef 
size and likelihood of successful recruitment. Such suggestions have led to considerable investment in fine-scale numerical hydrodynamic simulations of flows around individual reefs (Black 1994, Wolanski \& Sarsenski 1997).

Given the new evidence regarding larval locomotory capabilities, the relative importance of fine-scale current features for entrapping larvae must be reappraised. I will show that for many larvae the target presented during dispersal is not determined by the reef edge and the stagnation zone in its lee, but rather by the sensory zone within which larvae are able to orient.

Models that incorporate larval swimming are beginning to appear in the literature. These models predict a decrease in the number of larvae lost from the system when swimming is included (Werner et al. 1993, Wolanski et al. 1997). Models with swimming also predict a decrease in dispersal distances as the size of sensory zones is increased ( $M$. K. James pers. comm.). These 2 effects result from a narrowing of the gaps between reef targets through which larvae can pass without recruiting. Such findings indicate that the incorporation of directed swimming by late stage larvae can substantially alter model predictions.

The approach taken when modelling swimming behaviour has been to add a swimming term (that is independent of the currents) to the particle velocity inside Lagrangian tracking algorithms. Common to work on swimming is the assumption that the introduced component of velocity aims directly at the target destination (Foreman et al. 1992, Werner et al. 1993, Wolanski et al. 1997). The larval behaviour described by this assumption is, arguably, the simplest that can be examined, other than the case of purely passive dispersal. I compare the results obtained for this simplest active case with those from other sets of behavioural assumptions, and also pose questions regarding the consequences of different types of expected behaviour.

\section{Issues to be addressed}

This paper presents a series of models that describe the effects of larval swimming in determining the levels of supply of larvae to reefs when different sensory faculties are relied upon for far field orientation. The models have been designed to assess the relative sensitivities of supply rates to the choice and strength of sensory faculty, compared with other potentially significant factors. The aim of this exercise is to whittle down the potentially long list of control variables examined in dispersal-recruitment studies.

The models examine 4 different scenarios, separating them on the basis of the type of sensory faculty used, and the swimming strength of the larvae. The sensitivities of supply rates to different factors vary among these groups. These 4 scenarios are: (1) strong swimmers orienting towards current-independent cues; (2) weak swimmers orienting towards current-independent cues; (3) strong swimmers orienting towards current-dependent cues; and (4) weak swimmers orienting towards current-dependent cues.

The models show that the rate of larval uptake by reefs often depends sensitively on the threshold values at which signals become discernible by larvae. Therefore, quantifying the strength of sensory capabilities of larvae is not a question of purely academic interest. but assumes a fundamental importance for understanding recruitment rates and, consequently, for managing reef fish populations.

\section{METHODS}

The models are constructed in 2 horizontal spatial dimensions. Polar and Cartesian co-ordinates are used interchangeably,

$$
\begin{array}{ll}
\text { Cartesian to Polar } & \mathbf{x}=(x, y) \rightarrow(r \cos \theta, r \sin \theta) \\
\text { Polar to Cartesian } & (r, \theta) \rightarrow\left(\sqrt{x^{2}+y^{2}}, \arctan \frac{y}{x}\right)
\end{array}
$$

The Cartesian basis vectors are denoted by $\mathbf{i}$ and $\mathbf{j}$, and their polar equivalents by $\mathbf{e}_{r}$ and $\mathbf{e}_{\theta}$.

Sensory zones. Let the sensory zone, $S$, around the reef be that area within which larvae can detect and orient with respect to the reef. The size of the sensory zone will be determined by the weakest signal with respect to which a larva can orient. Throughout the paper this threshold value will be taken as a measure of the strength of the sensory faculty employed.

If the intensity or concentration of the signal is graphed as a function of position,

$$
I=I(x, y)
$$

then possible sensory zones comprise the interiors of the family of contours of the surface obtained,

$$
S=\{(x, y): I(x, y) \geq c\}
$$

indexed by the threshold signal value, $c$.

Current-independent cues: Assume that the current-independent signal is emitted by a fixed source, which is either distributed uniformly around the reef edge or is at the centre of the reef. Being unaffected by the currents, the signal propagates radially from this source. The intensity will diminish with distance, because of radial spreading. A reasonable assumption if sound is the stimulus is that the relative loss of intensity due to dissipation by the medium is negligible. 
Current-dependent cues: A current-dependent signal, such as a chemical tracer or patch of warmer water, is assumed to diffuse in accordance with Fick's Law,

$$
\frac{\partial I}{\partial t}=D_{1} \frac{\partial^{2} I}{\partial x^{2}}+D_{2} \frac{\partial^{2} I}{\partial y^{2}}
$$

where $D_{1}$ and $D_{2}$ are the diffusion coefficients in the $x$ and $y$ directions respectively. For a good discussion of sensory zones and taxis-based responses associated with diffusing stimuli, see Okubo (1980).

I present the solutions corresponding to a continuous point release of signal from the centre of the reef into a current, and take the steady-state approximation (see Appendix 2). The principle of superposition of solutions of the diffusion equation (Eq.4) implies that the solution corresponding to a continuous point release can be generated by taking the integral sum of instantaneous point solutions over time. The steady-state approximation is obtained by letting $t \rightarrow \infty$ in this sum. For further details regarding solutions of the diffusion equation, consult Carslaw \& Jaeger (1947) or Crank (1975).

A point release of signal perhaps best represents a chemotactic response by larvae where the release of the signal will be restricted to the locality of some cluster of organisms on the reef. If a spatial distribution for points of release of the signal is available, we would then take the integral sum of these solutions in space, i.e. if the locations of patches of habitat on the reef occupied by organisms releasing a pheromone are described by distribution $\Omega$, then the resulting solution would be

$$
\hat{I}=\int_{\Omega} I\left(x-x^{\prime}, y-y^{\prime}\right) \mathrm{d} A^{\prime}
$$

The specifics of the distribution of release points do not change the qualitative nature of the solution.

Velocity field. The velocity vector (v) of a larva is given by a contribution due to current advection, $\mathbf{v}_{a}$, and a swimming contribution, $\mathbf{v}_{\mathrm{s}}$ :

$$
\mathbf{v}=\mathbf{v}_{\tilde{a}}+\mathbf{v}_{\mathrm{s}}
$$

Initially, swimming is assumed to be unadjusted for current, i.e. $\mathbf{v}_{\mathrm{s}}$ is independent of $\mathbf{v}_{\mathrm{a}}$. Later I examine the likely realism and consequences of this assumption.

For simplicity, assume a circular reef geometry, with radius $R_{1}$. The methods and conclusions would be robust to the relaxation of this assumption by deforming the reef outline.

To restrict the study to the senses used to orient towards reefs, model calculations are stopped when the larvae enter some near-reef zone, radius $R_{2}$, by multiplying the velocity field by a characteristic step function, $\chi$ :

$$
\mathbf{v}=\left(\mathbf{v}_{\mathrm{a}}+\mathbf{v}_{\mathrm{s}}\right) \chi_{\left(R_{Z_{1} \infty}\right)}(r)
$$

The approach used to represent currents would be inappropriate close to the reef itself, and the models only examine far field orientation. Attempts at inferring the sense used to orient towards reefs out of pelagic waters from the distribution of late stage larvae in the near reef zone would be complicated by the inability of sampling procedures to separate newly arriving larvae from earlier arriving larvae that have yet to settle. This error would be aggravated by the ability of larvae to use local sensory cues to re-distribute themselves adjacent to favourable habitats on the reef (Doherty et al. 1996).

Currents: Initially, forcing is provided by a constant unidirectional current of speed $v_{a}$ and without loss of generality we choose the $x$-axis to lie along the direction of the flow,

$$
\mathbf{v}_{\mathrm{a}}=\left(v_{\mathrm{a}}, 0\right)
$$

in Cartesian co-ordinates. This rather gross simplification allows analytical solutions to be derived for some cases.

The models must also examine the role of re-circulatory features that form in the lee of reefs, and to this end an explicit, continuous, piecewise differentiable characterisation of such a velocity field was designed. The characterisation superimposes 2 opposing Rankine vortices, generating velocity components $v_{a}^{2}$ and $\mathbf{v}_{\mathrm{a}}^{3}$, upon idealised, irrotational flow round a cylinder, giving $\mathbf{v}_{a}^{1}$ (Kundu 1990).

The velocity components derived from a complex potential function for idealised flow round a cylinder of radius $R_{1}$ are

$$
\left(v_{r}^{1}, v_{\theta}^{1}\right)=v_{\mathrm{a}}\left(\left(1-R_{1}^{2} / r^{2}\right) \cos \theta_{1}-\left(1+R_{1}^{2} / r^{2}\right) \sin \theta\right)
$$

where $v_{\theta}=r \dot{\theta}$

The vortices are modelled as a core in a solid body rotation (constant vorticity, $\omega$ ), and an outer irrotational vortex (zero vorticity). Let $(\bar{X}, \bar{Y})$ and $(\tilde{r}, \tilde{\theta})$ correspond to a linear transformation of our usual co-ordinate system to allow re-positioning and re-scaling of the vortices. Then the velocity components given by each vortex of core width $a$ are

$$
\left(v_{\dot{r}}^{1}, v_{\dot{\theta}}^{l}\right)=\left\{\begin{array}{ll}
\omega(0, \tilde{r}) & \text { if } \bar{r}<a \\
\omega\left(0, a^{2} / \bar{r}\right) & \text { if } \bar{r} \geq a
\end{array} \text { for } i=2,3\right.
$$

The full current velocity field is given by

$$
\mathbf{v}_{\mathrm{a}}=\mathbf{v}_{\mathrm{a}}{ }^{1}+\mathbf{v}_{\mathrm{a}}{ }^{2}+\mathbf{v}_{\mathrm{a}}{ }^{3}
$$

The resulting velocity field and associated streamlines are shown for 1 set of parameter values in Fig. 1.

Larval swimming: When outside the sensory zone around the reef, a larva is assumed to be unaware of its location and to be advected passively by currents. On entering the sensory zone, $S$, the larva begins swimming towards the reef along gradients, $\nabla I_{1}$ of increase 


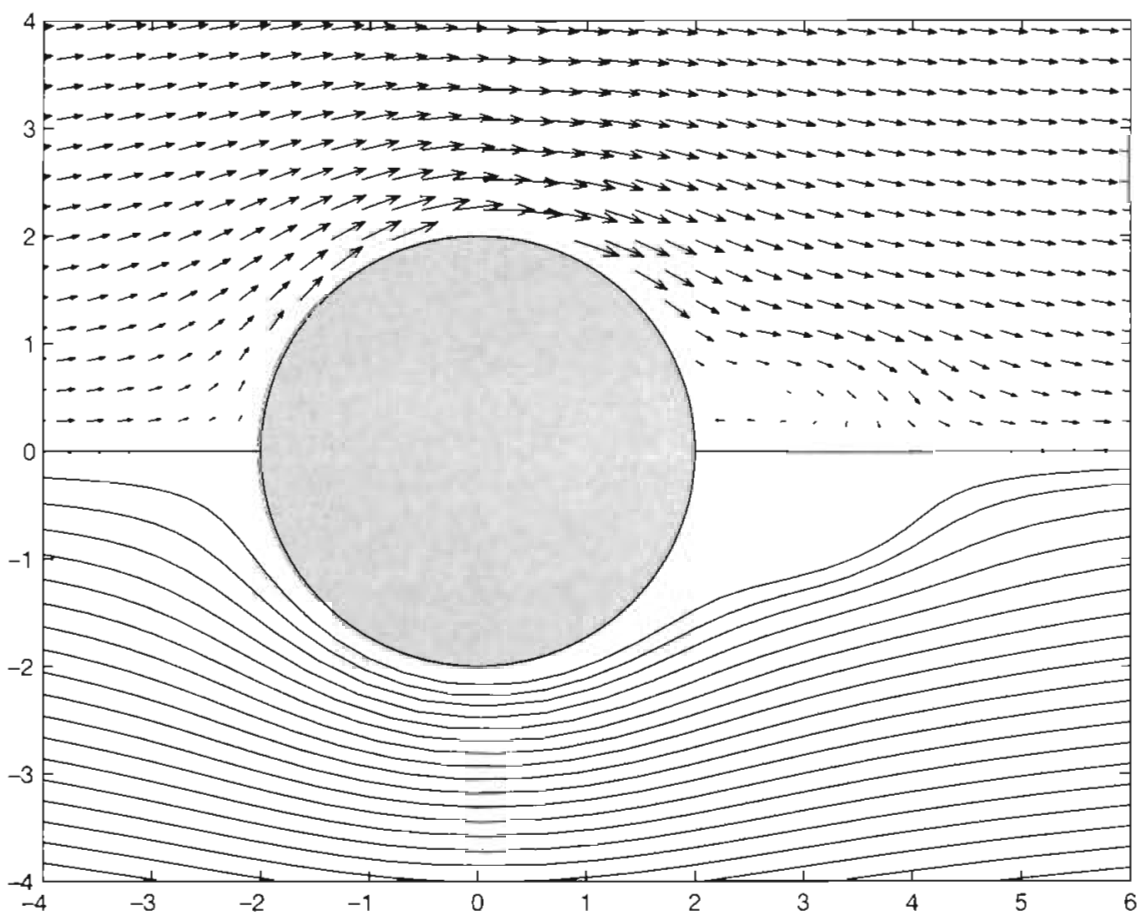

Fig. 1. Upper half plane: arrows represent velocity vectors from Eq. (11). Lower half plane: corresponding streamlines. Parameter values are: $v_{\mathrm{d}}, \omega, a, R_{1}, R_{2}=15 \mathrm{~cm} \mathrm{~s}^{-1}$, $1.08 \mathrm{~h}^{-1}, 0.25 \mathrm{~km}, 2 \mathrm{~km}, 2.1 \mathrm{~km}$, respectively

in the intensity or concentration of stimulus. This results in the swimming component of velocity,

$$
\mathbf{v}_{\mathrm{s}}=v_{\mathrm{s}} \chi_{\mathrm{s}}(x, y) \mathbf{n}
$$

where $\chi$ once more represents a characteristic step function, $\mathbf{n}$ is a unit vector in the direction of $\nabla I$, and $\nabla=(\partial / \partial x, \partial / \partial y)$ is the gradient operator.

Swimming speeds, $V_{\mathrm{s}}$, are assumed to be constant, and a variety of speeds is examined.

An important distinction separates those species and ages of larvae for which the sustainable swimming velocities do not exceed the mean current velocities, $v_{\mathrm{s}} \leq v_{\mathrm{a}}$, from those for which the sustainable velocities are greater than the mean current velocities, $v_{\mathrm{s}}>v_{\mathrm{d}}$. The former group shall be described as 'weak swimmers', and the latter as 'strong swimmers'.

Trajectories. Trajectories are given by the solutions of

$$
\frac{\mathrm{d} \mathbf{x}}{\mathrm{d} t}=\mathbf{v}, \quad \mathbf{x}(0)=\mathbf{x}_{0}
$$

Solutions are derived analytically where this is possible. In cases where an explicit analytical solution could not be derived, standard numerical solvers are employed.

Trajectories are obtained for initial conditions describing the arrival of a patch of larvae from upstream, to be consistent with the assumption of passive advection outside the sensory zones.
To examine the importance of the assumption that swimming strategies are current unadjusted, an alternative formulation to Eq. (13) is considered. In this extension a larva is assumed to anticipate the displacement it would have undergone by current advection during some future time interval $[t, t+\delta t]$, and to adjust the direction of its motion accordingly.

Rates of larval supply to the reef. Any larvae entering the sensory zone around the reef are considered to attempt to reach the reef, but only some will be successful. Define $E$ to be the effective target size of the reef, where $E$ is the subset of the sensory zone, comprising possible locations of larvae that will subsequently reach the reef successfully, i.e. $(x, y) \in E$, if a larva located at $(x, y) \in S$ at time $t$ will reach the near reef zone in time interval $[t, \infty)$, given that its motion is governed by Eq. (13).

The supply rate of larvae to the near-reef zone is equal to the inward flux (due to passive advection by currents) across the external boundary of $E$. I use the boundary width of $E$ perpendicular to the mean flow as an approximator of the supply rate of recruits to the reef. By doing so, I make an assumption regarding the far field hydrodynamic regime, namely, that the probabilistic distribution of release points for larvae across an upstream band is uniform.

The range of parameter values. Current speeds, $v_{a}$ : Frith et al. (1986) present data collected from a current meter near Lizard Island on the Great Barrier Reef (GBR). Sustained residual current speeds ranged from 10 to $17 \mathrm{~cm} \mathrm{~s}^{-1}$, which is typical for mid-shelf conditions in that region.

Swimming speeds, $\boldsymbol{v}_{s}$ : Leis \& Carson-Ewart (1997) measured in situ swimming speeds of late stage larvae around the same island. The average speed observed was $20.6 \mathrm{~cm} \mathrm{~s}^{-1}$. Their data suggest that late stage larvae of many species are strong swimmers. Stobutzki \& Bellwood (1997) measured the duration for which late stage larvae could maintain a speed comparable to currents around Lizard Island $\left(13.5 \mathrm{~cm} \mathrm{~s}^{-1}\right)$. They showed that larvae can swim constantly for days without rest, which would allow the modelled migration to proceed, even for very large sensory zones.

Size of sensory zone, S/threshold signal strength, $c$ : As discussed, this parameter is the one about which least is known. Again working in the same locale, Leis 
et al (1996) observed directed motion of larvae relative to the reef from a distance of over $1 \mathrm{~km}$ However, the cue that was being used for orientation was not known

Measurements of possible signals can be obtained over relatively large scales McCauley \& Cato (1998) documented nocturnal peaks in nolse levels around reefs discernible from up to $15 \mathrm{~km}$ away, which they attributed to the behaviour of planktivorous adult reef fish of some species. Doherty et al. (1996) observed plumes of warmer turbid waters up to $2 \mathrm{~km}$ south of One Tree Reef, GBR.

Logistıcal constraints limit experments designed to establısh which cues are, or are not, being utilised to much smaller scales of the order of metres (Sweatman 1988, Elliot et al. 1995, Stobutzki \& Bellwood 1998).

\section{RESULTS}

\section{Current-independent cues}

Current-independent signals propagate radially from a source. Assuming losses of energy to the medum to be negligible, radial spreading of the signal means that the power per unit length (of curcumference) decreases as the radius increases according to

$$
I(r, \theta)=\frac{I_{0}}{2 \pi r}
$$

This result is the 2-dimensional analogue of the inverse square law.
The corresponding intensity surface, $I_{1}$ and set of sensory zones, $S_{C}$ are shown in Fig. 2. Observe how the inverse relationship in Eq. (14) results in an asymptotic increase in size of sensory zone, as the threshold value $c$ decreases (or, equivalently, as the strength of sensory faculties increases). In particular, the maximum cross flow width of $S_{c}$ is given by

$$
\begin{aligned}
\text { Width }\left(S_{c}\right) & =\operatorname{diameter}\{I=\mathrm{c}\} \\
& =\frac{I_{0}}{\pi c}
\end{aligned}
$$

For the case where the currents are assumed constant, Eq. (13) becomes

$$
\begin{aligned}
\dot{r} & = \begin{cases}-v_{\mathrm{s}}+v_{\mathrm{a}} \cos \theta & \text { if }(r, \theta) \in S_{c} \\
v_{\mathrm{a}} \cos \theta & \text { otherwise }\end{cases} \\
r \theta & =-v_{\mathrm{a}} \sin \theta
\end{aligned}
$$

Analytical solutions can be obtained for this case (see Appendix 1) The paths followed by larvae are given by

$$
r= \begin{cases}\frac{A|\csc \theta-\cot \theta|^{\left|v_{s} / v_{\mathrm{u}}\right|}}{|\sin \theta|} & \text { if }(r, \theta) \in S_{c} \\ \frac{A}{|\sin \theta|} & \text { otherwise }\end{cases}
$$

The constant of integration $A$ is determined from the initial conditions, $\mathbf{x}(0)=\mathbf{x}_{0}$.

The ratio of sustainable swimming speed to current speed $v_{\mathrm{s}} / v_{\mathrm{a}}$ is an umportant parameter. If we vary this ratio, the solution set of trajectories undergoes a critical qualitative change (a topological discontinuity or bifurcation) when the ratio equals 1 (Appendix 1). In other words, the solution set for strong swimmers is qualitatively different from that for weak swimmers. We observe therefore that our a priori division of scenarios emerges naturally from examination of the solution set.

\section{Strong swimmers orienting towards current-independent cues}

The trajectories for strong-swimming larvae $\left(v_{s}>v_{a}\right)$ responding to a currentindependent cue in the presence of a constant current field are shown in Fig. 3a. All larvae entering the sensory zone are able to reach the reef. Therefore the effective size of target presented by a reef to dispersing larvae is the full sensory zone around it, $E=S_{c}$. The asymptotic re-
Fig. 2. Intensity surface, I for current-independent cue from Eq (14). Surtace raised by adding 5 to $I$ to allow superposition of contour plot of corresponding sensory zones $I_{0}=100$ 
a

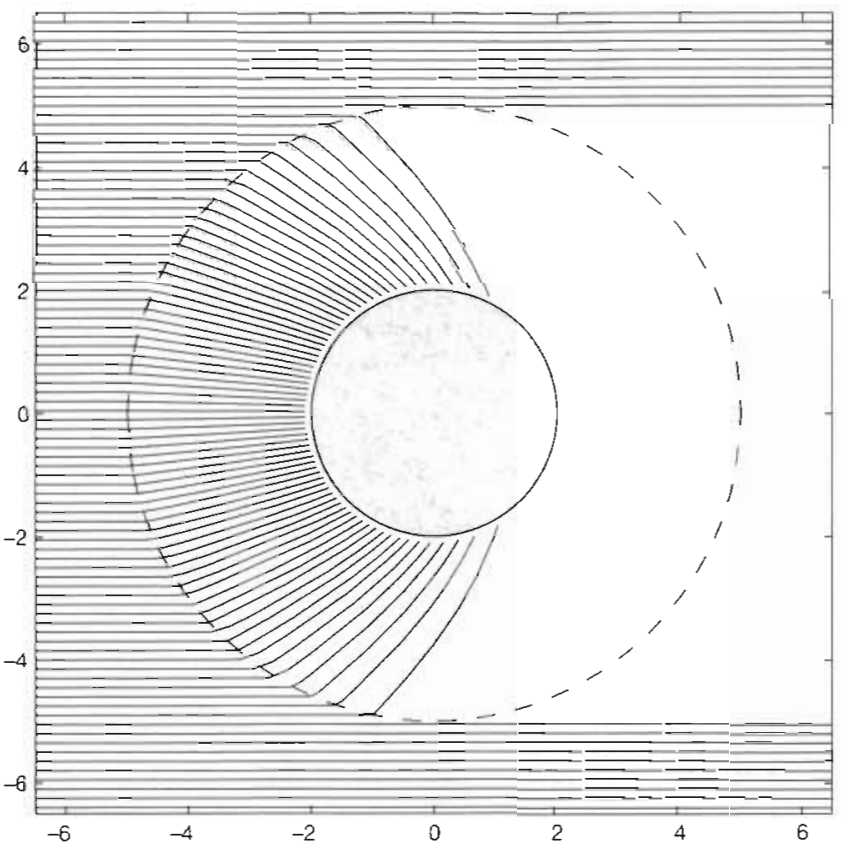

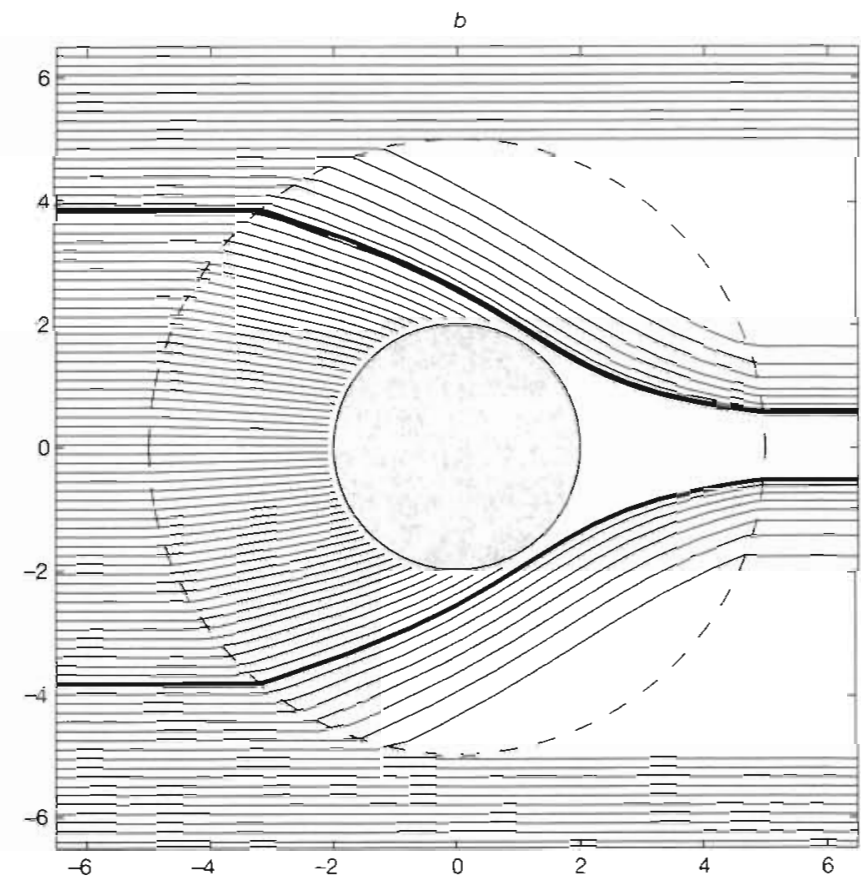

Fig. 3. Trajectories from Eq. (17) for current-independent cues. $v_{\mathrm{a}}=15 \mathrm{~cm} \mathrm{~s}^{-1}$ Sensory zones marked with dashed line; edge of sensory zone $3 \mathrm{~km}$ from edge of reef. (a) Trajectories for strong-swimming larvae with $v_{5}=20 \mathrm{~cm} \mathrm{~s}^{-1}$ (b) Trajectories for weakswimming larvae with $v_{\mathrm{s}}=8 \mathrm{~cm} \mathrm{~s}^{-1}$ Separatrices marked with thick black line

lationship in Eq. (15) then relates the rate of larval supply to the strength of the sensory faculty used for orientation, as shown in the outermost curve in Fig. 4.

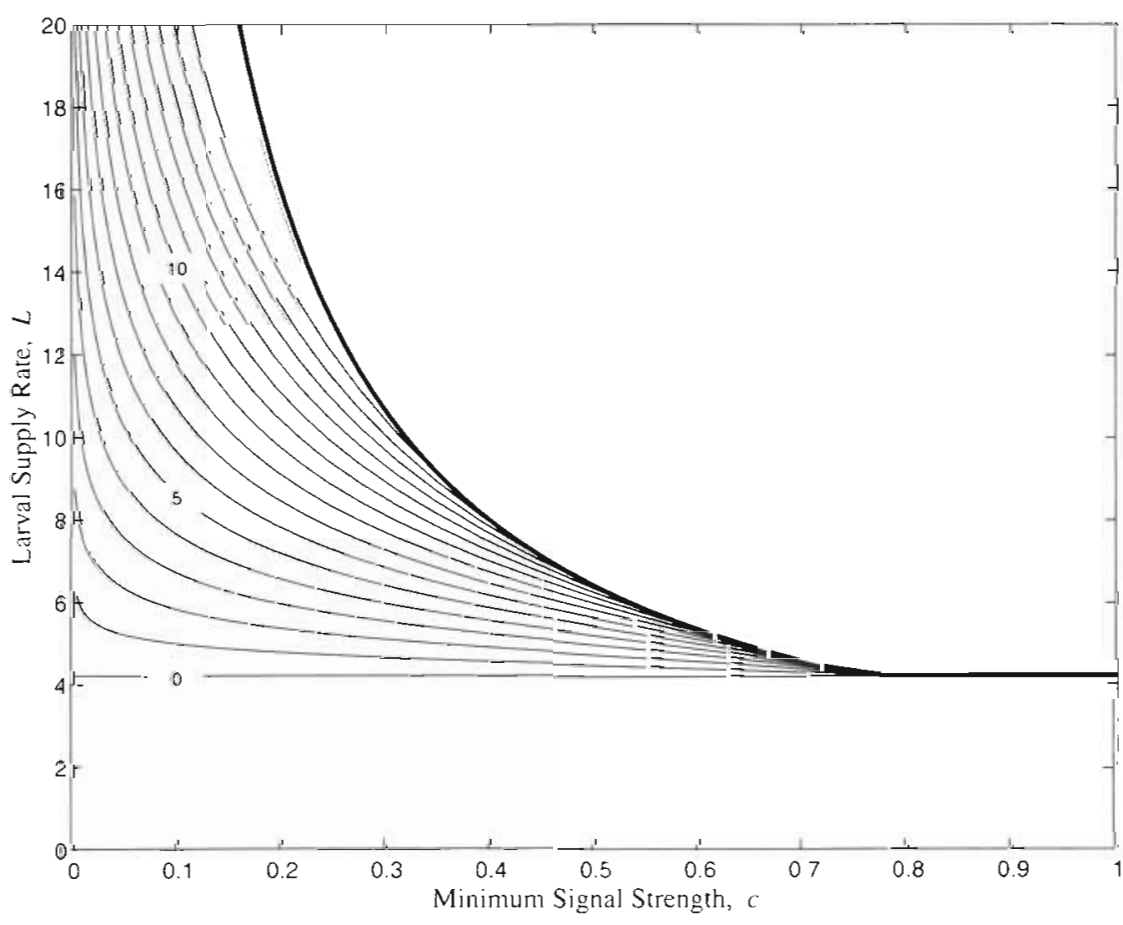

Fig. 4. Estimated supply rates of larvae against threshold signal strength. Outermost (bold) curve describes all possible swimming speeds for strong swimmers. Other curves show swimming speeds for weak swimmers in $\mathrm{cm} \mathrm{s}^{-1}$ Incidental recruitment alone guarantees fixed minimum recruitment rate
Inclusion of the effects of retardation of the currents in the eddy field behind the reef is unnecessary, because all larvae entering the sensory zone can overcome the open water currents and reach the near-reef zone successfully.

The assumed swimming behaviour of larvae has the effect of funnelling the trajectories in towards the target presented by the reef. This increases larval density above background patch levels and leads to observable aggregations of larvae.

The curved nature of the trajectories in Fig. 3a is due to the assumption that the swimming strategy employed is not adjusted for currents. A larva is assumed to aim directly at the reef, but has to correct its course continuously, because, relative to it, the reef presents a moving target. As all larvae entering the zone are able to swim at rates above the net current, this rather inefficient swimming strategy does not affect the ability of larvae to reach the reef. It does, however, have implications for the length of time taken to reach the reef and hence the amount of energy expended in doing so. 
Weak swimmers orienting towards currentindependent cues

The trajectories for weak-swimming larvae $\left(v_{S} \leq v_{a}\right)$ responding to a current-independent cue in the presence of a constant current field, given by Eq. (17), are shown in Fig. 3b. In this case not all larvae entering the sensory zone are able to reach the reef, although under the model assumptions all will try. A division of the patch results, separating those larvae that successfully reach the reef from those that do not. The change in the structure of the solutions occurs as $V_{\mathrm{S}} / v_{\mathrm{d}}$ passes through 1, i.e. as we shift attention from strong to weak swimmers. With this change we see the appearance of 2 dividing trajectories that split the patch, separating larvae that can reach the near-reef zone from those that cannot.

The 2 dividing trajectories, or 'separatrices', enclose all trajectories of larvae reaching the reef successfully. The separatrices are tangential to the boundary of the near-reef zone at the points

$$
(x, y)=\left(R_{2} \frac{v_{\mathrm{s}}}{v_{\mathrm{a}}}, \pm R_{2} \sqrt{1-\left(\frac{v_{\mathrm{s}}}{v_{\mathrm{a}}}\right)^{2}}\right)
$$

(for details consult Appendix 1). The width of the jaws formed by the separatrices is dictated by the ratio of swimming speed to current speed, and the size of the sensory zone. The effective target size of the reef is the intersection of the area between the separatrices and the sensory zone. The relationship between the strength of sensory faculty used, the ratio of $v_{5}$ to $v_{a}$ and the rate of larval uptake is depicted in Fig. 4.

Observe that some trajectories pass very near to the back of the reef, and there is the likelihood of an aggregation of unsuccessful swimmers in the lee of the reef in Fig. 3b. This suggests that for weak-swimming larvae the eddy field and stagnation zone that can form behind reefs could help increase the proportions of successfully recruiting larvae.

To explore this possibility, a patch of larvae was released into the current field Eq. (11) shown in Fig. 1. Solutions to Eq. (13) were computed numerically. The resulting trajectories are shown in Fig. 5. The increased uptake of larvae due to the retention of particles in the eddy field is apparent. By retarding the flow, the eddy field allows larvae that can enter it to reach the near-reef zone. Thus, the effect of the eddy field is to widen the jaws formed by the separatrices (which no longer begin from the edge of the near-reef zone, but from the outer edge of the eddy field), and, thereby, to increase the supply rate of larvae to the reef.

In the absence of the eddy field, larvae were predicted to arrive from upstream, but this extension of

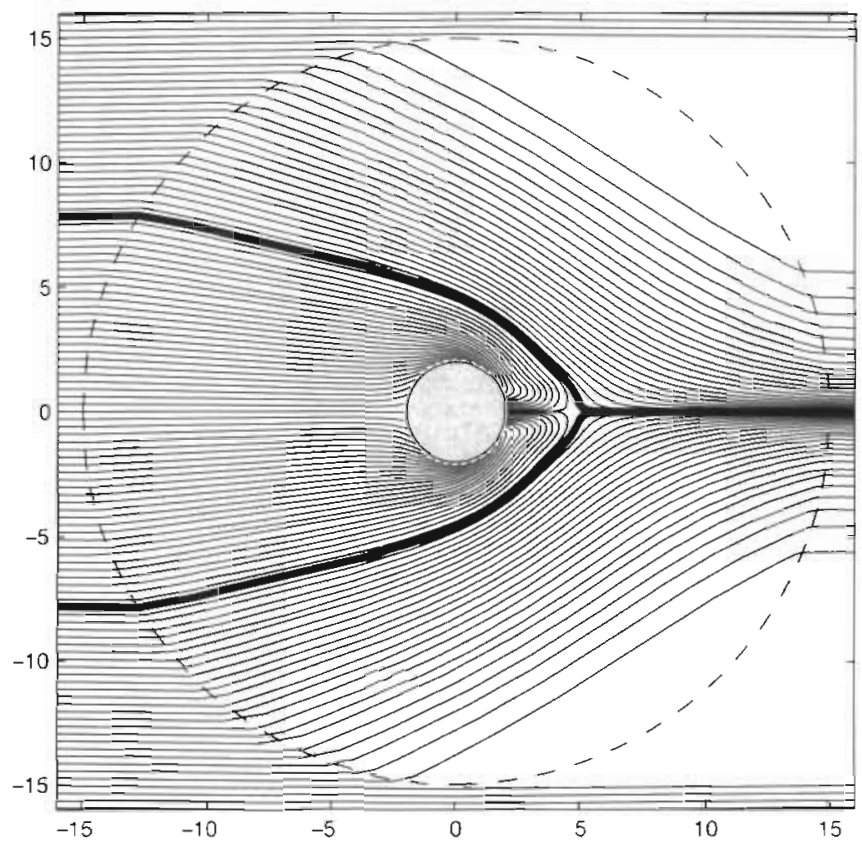

Fig. 5. Trajectories for current-independent cues with eddy field incorporated. $v_{\mathrm{a}}=15 \mathrm{~cm} \mathrm{~s}^{-1}$. Trajectories for weak-swimming larvae with $v_{\mathrm{s}}=8 \mathrm{~cm} \mathrm{~s}^{-1}$. Separatrices marked with thick black line. Sensory zone marked with dashed line; edge of sensory zone is $15 \mathrm{~km}$ from edge of reef

the model suggests the likelihood of some larvae arriving through the eddy field to the back of the reef.

The trajectories for weak swimmers are again characterised by their curving shape, because of the assumption that swimming strategies are current unadjusted. In this case, however, the cost of the inefficient strategy is realised directly in the numbers of larvae that can successfully reach the reef. A larva that possessed the requisite swimming capability to reach the reef, had it followed a more efficient strategy, could now no longer be able to do so.

To examine the significance of this assumption, an adaptation of Eq. (13) for the case of a constant current (Eq. 8) was considered. Suppose now that a larva has the capability to anticipate the effects of the current, or, equivalently, the relative 'displacement' of the reef with respect to itself, for some time $\delta t$ in the future; the larva can then plot an adjusted course. (Note that if a larva can detect a reef, it can detect the effects of currents by not swimming and tracking the movement of the target presented by the reef.) Let $\mathbf{p}$ be the position vector that would be occupied at time $t+\delta t$ by a larva at $\mathbf{r}$ at time $t$, if it were advected passively in the intervening time period, and so $\mathbf{p}=\mathbf{r}+v_{2} \delta t \mathbf{i}$. The new swimming velocity is then

$$
\mathbf{v}_{\mathrm{s}}=-V_{\mathrm{s}} \hat{\mathbf{p}}
$$

where $\hat{\mathbf{p}}$ is a unit vector in the direction of $\mathbf{p}$. An application of the sine rule inside the triangle formed from $\mathbf{r}$, 
Fig. 6. Application of sine rule inside triangle gives Eq. (21) for current-adjusted swimming

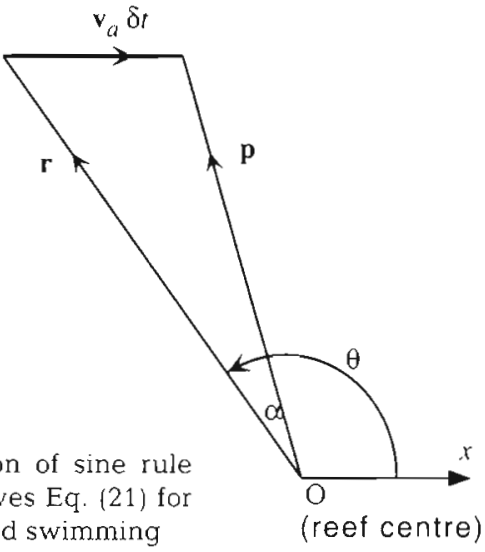

$v_{a} \delta t i$ and $\mathbf{p}(\mathrm{Fig}, 6)$ shows that

$$
\hat{\mathbf{p}}=\cos \alpha \mathbf{e}_{\mathrm{r}}-\sin \alpha \mathbf{e}_{\theta}
$$

where $\alpha$ is the angle between $\mathbf{r}$ and $\mathbf{p}$ given by

$$
\alpha=\arctan \left(\frac{\sin \theta}{r /\left(v_{\mathrm{a}} \delta t\right)+\cos \theta}\right)
$$

Note that if $\delta t=0$, the zero anticipation case, $\alpha$ is zero by definition and we recover Eq. (16), describing current-unadjusted swimming as before. If $\delta t$ is increased the trajectories straighten out and follow more direct courses to the reef. This improved efficiency means more larvae recruit successfully. The variations in a trajectory as $\delta t$ is increased are illustrated in Fig. 7.

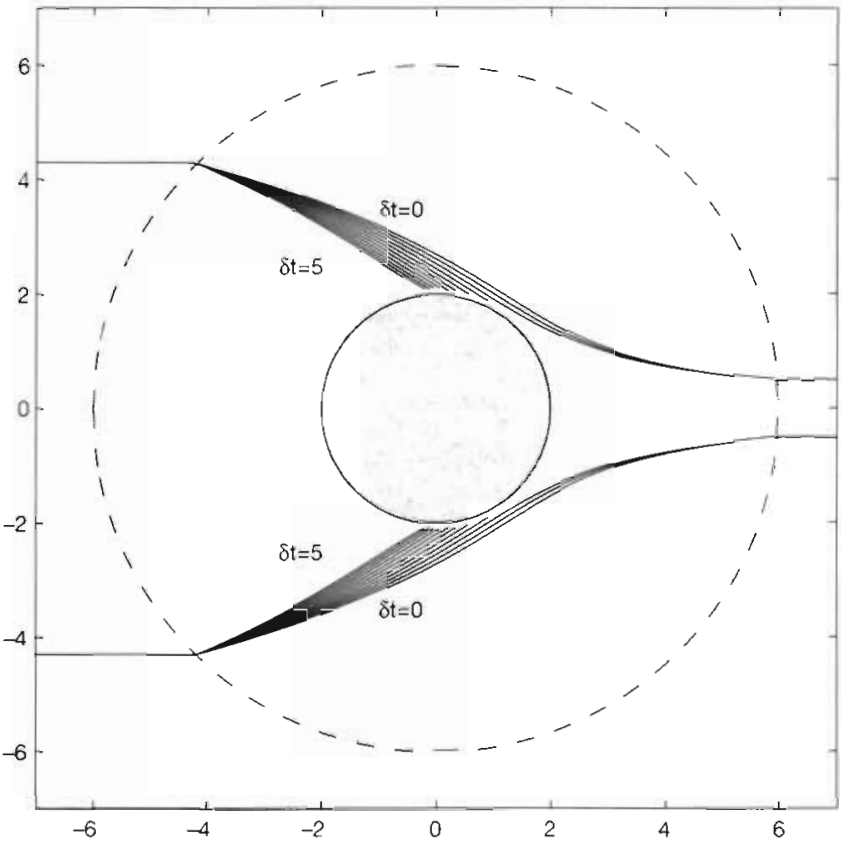

Fig. 7. Trajectories for current-independent cues with differing capabilities to anticipate effects of currents. Larvae released from the same upstream location. $v_{\mathrm{a}}=15 \mathrm{~cm} \mathrm{~s}^{-1}$. Trajectories for weak-swimming larvae with $v_{\mathrm{s}}=8 \mathrm{~cm} \mathrm{~s}^{-1}$ Anticipation times increased from 0 to $5 \mathrm{~h}$ in increments of $30 \mathrm{~min}$. Larvae relying on more efficient strategies reach the reef successfully; those with less efficient strategies do not

\section{Current-dependent cues}

Assuming the continuous release of some current-dependent cue from a point source at the centre of the reef into a constant current (Eq. 8), and taking the steady-state approximation, we obtain the intensity surface

$$
I(x, y)=\frac{I_{0}}{2 \pi \sqrt{D_{1} D_{2}}} \mathrm{e}^{v_{4} x /\left(2 D_{1}\right)} K_{0}\left(\frac{V_{\mathrm{a}} q}{2 \sqrt{D_{1}}}\right)
$$

where $K_{0}(z)$ is the modified Bessel function of order zero, and we define $q=\left(x^{2} / D_{1}+y^{2} / D_{2}\right)^{1 / 2}$. (For the derivation of this solution consult Appendix 2.) This surface and the corresponding sensory zones from Eq. (3), are shown in Fig. 8. The sensory zones are Gaussian plumes, achieving their maximum width some dis-

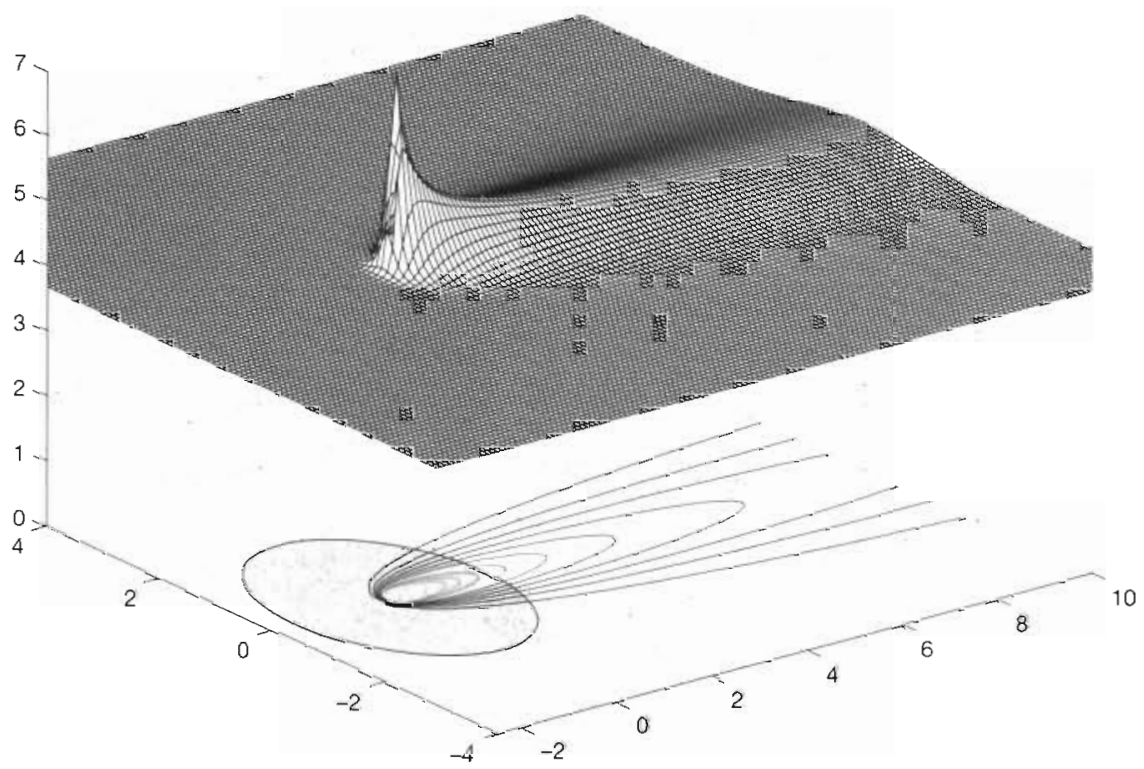

Fig. 8. Intensity surface, $I$, for current-dependent cue from Eq. (22). Surface raised by adding 5 to $I$ to allow superposition of contour plot of corresponding sensory zones. $I_{0}=30$ 
tance downstream of the reef. The sizes of sensory zones increase rapidly as $c_{\text {, the }}$ threshold value, is decreased.

The swimming component of the velocity field, $v_{\mathrm{s}}$ acts in the direction of $\nabla I$, and is given by

$$
\mathbf{v}_{\mathrm{s}}=v_{s}\left(\frac{a}{\sqrt{a^{2}+b^{2}}}, \frac{b}{\sqrt{a^{2}+b^{2}}}\right)
$$

where

$$
(a, b)=\nabla I
$$

are explicitly given in Appendix 2.

\section{Strong swimmers orienting towards current-dependent cues}

The trajectories for strong-swimming larvae $\left(v_{\mathrm{s}}>v_{\mathrm{a}}\right)$ responding to a current-dependent cue in the presence of a constant current field are shown in Fig. 9a, and the relationship between strength of sensory faculty used and the supply rate of larvae is shown by the upper curve in Fig. 10. The sensory zones have effectively no upstream area, so that arrival in the near-reef zone from upstream is purely inciden-

tal, due to passive advection. Larvae only enter the sensory zone once they have passed by the reef, and then swim back against the current.

Inside the sensory zone the trajec-
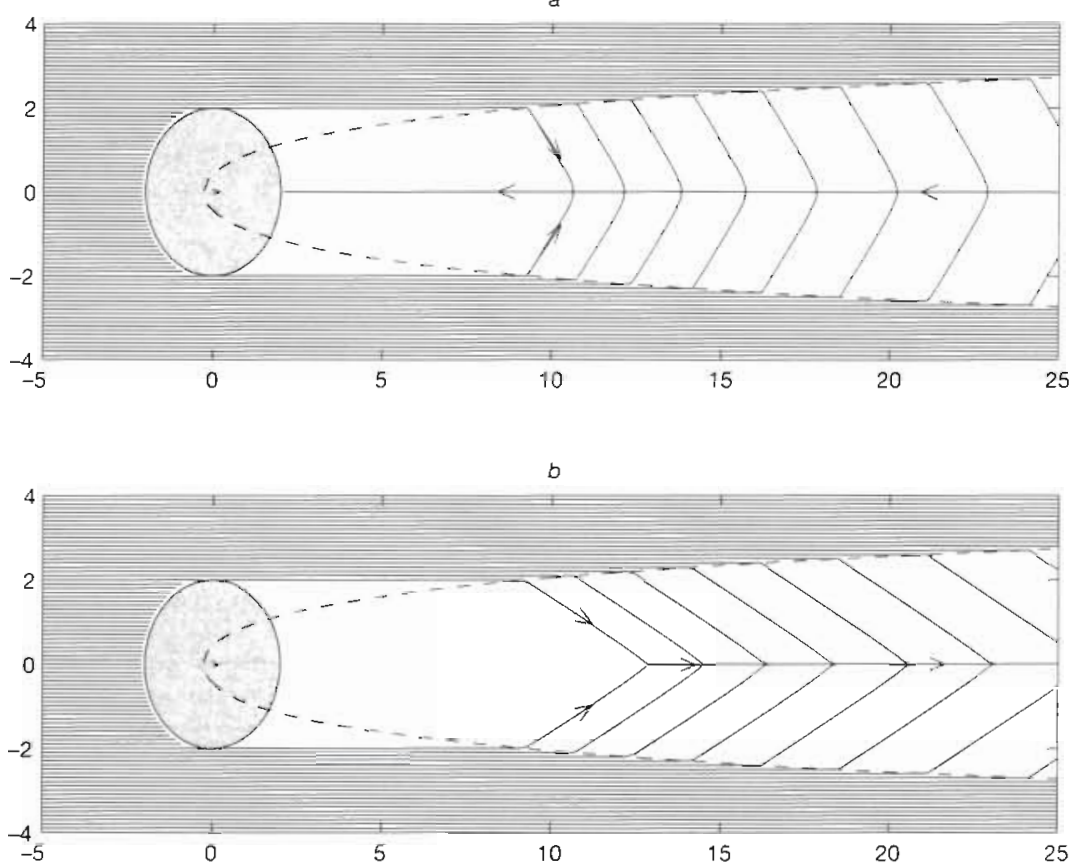

Fig. 9. Trajectories for current-dependent cues. $v_{a}=15 \mathrm{~cm} \mathrm{~s}^{-1}$ Sensory zones marked with dashed line. (a) Trajectories for strong-swimming larvae with $v_{\mathrm{s}}=20 \mathrm{~cm} \mathrm{~s}^{-1}$ (b) Trajectories for weak-swimming larvae with $v_{\mathrm{s}}=8 \mathrm{~cm} \mathrm{~s}^{-1}$ tories follow a pronounced L-shape, because on the edges of the plume (in Fig. 8), the greatest change in concentration is encountered when moving in towards the plume's spine $(|b| \gg|a|)$. It is only once the vicinity of that spine has been reached that the larvae would turn towards the reef and approach from downstream $(|b|<|a|)$. This results in a tightly aggregated arrival pattern in the near-reef zone from downstream.

As for strong-swimming larvae orienting towards current-dependent cues, any larva entering the sensory zone will be expected to reach the reef successfully, because it will have the capacity to overcome the currents. However, ignoring fine-scale current features around reefs will no longer be so robust an assumption as it was when working with species which rely on currentindependent cues, because those finescale flow features will determine how the stimulus will spread downstream, and thereby the precise nature of the sensory zone. 
Weak swimmers orienting towards current-dependent cues

If the cue used to orient towards reefs is current. dependent, then it will only be discernible from downstream of the reef. Weak-swimming larvae which are not able to sustain swimming speeds greater than the current speeds $\left(v_{\mathrm{s}} \leq v_{a}\right)$ will not be able to use such cues to orient towards reefs. Even if these weak-swimming larvae can detect a reef from downstream, they do not possess the requisite swimming capabilities to overcome the velocity field and return. Therefore, as is apparent from the trajectories shown in Fig. 9b, the only successful intersections of these larvae with the reef are incidental (Fig, 10).

\section{DISCUSSION}

\section{Review of assumptions}

\section{Simple current field}

The current fields used in the model are deliberately simple. One striking conclusion from the results is that in some cases working with a simple characterisation of the current field will suffice. This is true when studying the rate of uptake of strong-swimming larvae. These larvae have the ability and, by assuming directed motion, the motivation to overcome variations in the current field. For these species the trend towards constructing ever more accurate descriptions of the current field around individual reefs over finer and finer scales is an expensive task of limited utility.

For weak-swimming larvae orientating with respect to a current-independent cue, the halo of re-circulatory features (Kingsford et al. 1991) still has an important role to play in retarding the flow, and, thereby, increasing the numbers of larvae that can recruit. In this situation, describing the fine details of the flow in the eddy field is less important than approximating the boundaries of the zone in which the flow is retarded.

The hydrodynamic models of Black (1993) indicate that tidal currents are important in determining how passively advected material arrives at reefs. An extension of the present work examining how the inclusion of tidal currents alters the conclusions is nearing completion. For both weak and strong swimmers the movement towards a reef from distances of a few kilometres can take several hours. These time scales are such that shifts in the current patterns with tides are significant, and do not necessarily average out over the tidal phase, i.e. larvae could be exposed to either the flood or ebb tide alone during movement towards the reef. For current-independent cues, preliminary results suggest an increase in the supply rate of strong swimmers when tides are included. This increase results from the tidal oscillation carrying additional larvae into the sensory zone around the reef; these larvae can then reach the reef successfully. There is little effect on the supply rate for weaker swimmers, because any additional larvae carried into the sensory zone enter it from outside of the separatrices. When tidal currents are included, the trajectories followed to the reef are generally less direct than otherwise. Accurate descriptions of tidal flows around reefs will be important in describing the sensory zones generated by passively advected tracers of current-dependent cues, such as pheromones or patches of warmer water. Perhaps the most important result from the inclusion of tides is that, while tides have some effect, the strength of the sensory faculty remains the critical determinant of supply rates.

\section{Swimming behaviour}

A number of models have considered the simplest active case, namely, the case where the swimming velocity points directly at the target destination (Foreman et al. 1992, Werner et al. 1993, Wolanski et al. 1997). By explicitly modelling the sensory cue used for orientation, and manipulating the directional derivative, I have motivated this case (of current-unadjusted swimming in response to a current-independent cue), and compared it with the behaviour given by a reliance on other (current-dependent) sensory faculties.

The assumption in the literature that the swimming velocity component is independent of the background current velocity should be questioned. From the trajectories (Figs. $3 \&$ 8) we see that to aim directly along gradients in the stimuli is an inefficient swimming strategy. The more efficient strategy, well known to anyone who has ever piloted a boat or been swimming in a current, is to aim upstream of your target, so that your net velocity is in the intended direction. By considering the relative 'movement' of the reef with respect to a passively advecting larva, we see that the situation is directly analogous to a terrestrial organism trying to catch a moving target. In such situations, insects and mammals have been observed to follow interception paths by anticipating future movements of the target (Wehner 1997). Might then we not expect larval fish to anticipate (imperfectly) the effects of currents, to plot interception paths to the reef, and then to follow a current-adjusted course?

Relaxing the assumption that swimming is unadjusted for current reduces the energy spent by larvae swimming to the reef. Only in the case of weak swim- 
mers orienting towards a current-independent cue would the relaxation of this assumption change the rate of uptake of larvae by the reef by widening the separatrices. In all cases it would alter the lines of approach to the reef followed by the larvae.

\section{Summary of results}

The models illustrate that a 4 -way categorisation of possible movement patterns is appropriate, separating strong and weak swimmers relying on currentdependent and -independent stimuli. Measurements of sustained swimming speeds, and field or laboratory experiments to detect larval response to different signal patterns, would position a particular species within 1 of these 4 subsets

\section{Strong swimmers orienting towards current-independent cues}

Species that can sustain swimming speeds greater than the current speeds around reefs are able to overcome unfavourable currents when migrating towards the reef, even if the swimming strategy employed is relatively inefficient. Therefore, the effective target size that a reef presents to larvae is the size of the sensory zone around it. For species that orient towards a current-independent cue, the sensory zone is a radial expansion of the reef itself.

The actual speed maintained by strong swimmers in the field has less relevance than the knowledge of whether that speed can be greater than the speeds of the currents around reefs. Gathering data on actual speeds maintained in the field is a challenge fraught with logistical difficulties (Leis \& Carson-Ewart 1997). However, if we assume that larvae have a strong motivation to reach a reef in some period prior to settlement, then having measurements of larval capabilities could suffice. Measurements of sustainable swimming speeds can more readily be obtained from laboratory 'race-way' experiments (Stobutzki \& Bellwood 1994, 1997).

Consideration of the nature of fine-scale current features around reefs seems unhelpful when assessing the rates of recruitment of strong swimmers relying on current-independent cues. The signal towards which these larvae orient is unaffected by features of the flow field, and the larvae themselves can overcome any unfavourable currents within such features. Therefore, for such species, the hypothesis that the entrapment of advected material in re-circulatory features in the lee of reefs is important in determining rates of larval supply (Dight \& Black 1991, Kingsford et al. 1991) is redundant.
When considering the rates of supply of larvae to reefs, a factor that is much more significant than either the actual swimming speed maintained by strong swimmers or the fine detail of the current flow around reefs is the sensitivity of the sensory faculty used for orientation. The inverse relationship between the detection strength of the sensory faculty and size of sensory zone means that very small changes in the threshold signal strength result in very large changes in the size of sensory zone, and, thus, in predicted rates of larval supply.

Observations of arrival patterns of larvae to the nearreef zone could be obscured by the distribution of earlier arriving larvae. Proceeding with due caution then, the trajectories in the model suggest that movement towards the reef begins from upstream, in agreement with the field data of Wolanski et al. (1997). Comparing this set of trajectories with those of strong swimmers relying upon current-dependent cues, the relative distance that larvae relying on current-independent cues have to swim is substantially shorter. This fact could be significant if energetic expenditure prior to settlement correlates with subsequent juvenile mortality rates (Stobutzki 1997, McCormick 1998), or if the source of the signal used for orientation is intermittent (McCauley 1997).

Swimming towards a fixed target introduces nonzero divergence terms into the velocity field dictating larval trajectories. The increased density of larvae around the reef when compared with the background patch density outside the sensory zone (Fig. 3a) is a result of the action of these divergence terms. Such aggregation would have important dynamic consequences if larval mortality around reefs were a density-dependent process (Armsworth \& Bode 1999).

\section{Weak swimmers orienting towards current-independent cues}

Weak swimmers are assumed unable to overcome the open water currents. However, if the sensory mechanism used to detect reefs is current-independent, weak-swimming larvae can still use their swimming capabilities in such a way as to enhance the supply rate of larvae to the reef. They do this by swimming towards the reef whilst still upstream, where $\mathbf{v}_{a}$ and $\mathbf{v}_{\mathrm{s}}$ are not acting in direct opposition to each other.

In this case, the effective target size presented by the reef is no longer the full sensory zone, but is determined by an interaction of the strength of the sensory faculties employed and the maximum sustainable swimming speed. The effective target size is demarcated by the points of intersection of the separatrices and the boundary of the sensory zone. Therefore, for 
species in this category, actual field measurements of sustainable swimming velocities are important in determining the supply rate of larvae to reefs.

The relationship between rate of uptake and swimming speed is less significant than that between the rate of uptake of larvae and the sensitivity of sensory faculty. To see this in Fig. 4 consider fixing $v_{\mathrm{s}}$ (i.e. follow 1 particular curve) and letting $c$ vary; as $c \rightarrow 0$, $L \rightarrow \infty$, where $L$ is the supply rate. Now fix $c$ and let $v_{\mathrm{s}}$ vary (i.e. move vertically across the curves); as $v_{\mathrm{s}} \rightarrow v_{\mathrm{a}}$ $L \rightarrow \bar{L} \ll \infty$, where $\bar{L}$ is some finite supply rate.

Just as the maximum sustainable velocity partly determines the larval supply rate to reefs, the efficiency of the swimming strategy employed will also affect it. An inability to anticipate future effects of current advection incurs a direct cost in numbers of larvae that are able to recruit to the reef.

Fine-scale features in the lee of reefs play a significant role in this case. While entrapment in these features is no longer a passive process, the retardation of the flow field in the lee of the reef widens the jaws of the separatrices, and allows a greater degree of successful recruitment. Without the inclusion of an eddy field, the trajectories predict an upstream aggregation entering the near-reef zone, which is above mean patch density. With the inclusion of an eddy field, the trajectories predict the arrival of downstream aggregations of larvae through the stagnation zone produced. These model findings are in agreement with those predicted by the simulations of Wolanski et al. (1997) of swimming larvae orienting towards sound, which suggested an aggregation of weak-swimming larvae in the lee of the reef. Important parameters in this situation are the width of the eddy field and strength of the mean current field within this zone.

Strong swimmers orienting towards current-dependent cues

All strong-swimming larvae that enter the sensory zone corresponding to some current-dependent mechanism have the capacity to reach the near-reef zone successfully. As before, precise measurements of swimming speeds in the field are less relevant than the initial determination of whether these larvae are capable of swimming at speeds greater than current velocities. Fine-scale current features do not directly influence the net velocity of the larvae, because their influence can be overcome.

The sensory zones traced out by current-dependent signals form downstream plumes, with effectively no upstream area. The sensory zones achieve their maximum width some distance downstream of the reef itself. A comparison of rate of larval supply and strength of sensory faculty employed for orientation demonstrates the familiar inverse and asymptotic relationship (Fig. 10), Once more then, the strength of the sensory faculty used to orient towards reefs is the most critical determinant of rates of larval supply.

Whilst heeding earlier warnings given about the difficulties in observing arrival patterns of larvae in the near-reef zone, we note the pronounced pattern in the trajectories in Fig. 9a. The fore-reef edge of the nearreef zone receives only incidental arrivals of larvae from upstream, but a very tightly aggregated arrival of swimming larvae from downstream is apparent. Earlier comments regarding possible implications of larval aggregations in deciding mortality rates apply. The trajectories of swimming larvae, which first pass by the reef and then return from downstream, illustrate why reliance on current-dependent sensory mechanisms incurs a higher energetic cost than reliance on currentindependent cues, because larvae must swim in direct opposition to the current to reach the reef.

While direct effects of fine-scale current features on strong-swimming larvae can be ignored, indirect effects cannot. Complex current patterns in the lee of reefs will determine how the tracer that provides these larvae with a cue for orientation is dispersed. The analytical approach utilised in this paper provides a simplified approximation of the dispersal of tracers in such current fields. Numerical simulations that have been designed specifically to study the advection of passive tracers around reefs would provide better tools for demarcating these sensory zones (Wolanski \& Sarsenski 1997).

\section{Weak swimmers orienting towards current-dependent cues}

The conclusions of this case are stark. Weak-swimming larvae that cannot overcome currents cannot rely on current-dependent cues to orient towards reefs. As current-dependent sensory zones have effectively zero upstream area, entry into these zones only occurs downstream of the reef, from whence return by weakswimming larvae to the reef is impossible. Including the retardation of current in the eddy field behind reefs does not alter this conclusion, because the outward diffusion of the tracer is inhibited by the eddy zone, and entry into the sensory zones only occurs further downstream. Therefore, the arrival in the near-reef zone of weak-swimming larvae that rely on current-dependent cues is an entirely passive process. Further consideration of the effects of behaviour in enhancing the rates of uptake of such larvae by reefs may be unnecessary. 


\section{Ecological implications}

The models examine biophysical interactions during settlement from the pelagic environment. The ecological parameters considered are the swimming and sensory capabilities of settling larvae. Specifically, the models quantify constraints imposed upon behaviour during settlement by hydrodynamics. Strong swimmers are effectively unconstrained by the environment, and are able to utilise current-dependent or -independent cues for orientation. Any strong swimmer that can sense a reef is able to reach it. Therefore, for strong-swimming species the constraints upon larval supply are biological, and, moreover, the extent of sensory capabilities will be an indicator of supply rates. The behaviour of weak swimmers during settlement is constrained by both physical and biological factors. Weak swimmers will only be able to employ currentindependent stimuli for far field orientation towards reefs. To illustrate these conclusions and highlight their significance, I relate them to 2 particular families: the Acanthuridae and the Apogonidae.

Acanthurids have highly specialised larvae (Leis 1991). Late stage acanthurid larvae are strong swimmers, and are able to travel upstream through a current field (Leis \& Carson-Ewart 1997, Sancho et al. 1997. Stobutzki \& Bellwood 1997). These larvae are capable of directed motion, of exercising selectivity between benthic habitats whilst travelling at high speeds, and show other complex motile behaviour (Sancho et al. 1997). These observations suggest late stage acanthurid larvae possess advanced sensory capabilities. Some acanthurids can delay metamorphosis, and thereby exercise control over settlement time (McCormick 1999). This ability allows them to exercise control over the set of environmental conditions experienced during settlement. Thus, acanthurids would be classed as strong swimmers. From the model, we conclude that local currents do not constrain settlement patterns for acanthurids, and that whatever constraints are imposed upon settlement behaviour are biological. Specifically, the model predicts that one critical constraint is the extent of the sensory capabilities for far field orientation. Acanthurid larvae could rely on current-dependent or -independent cues, or some combination of the two. Such larvae would be unrestricted by local hydrodynamics in habitat choice or time of settlement. Therefore, one may expect recruitment patterns for acanthurids and similar species to be more predictable in both space and time than those for less capable species.

Apogonids are weak swimmers (Leis \& CarsonEwart 1997, Stobutzki \& Bellwood 1997). Both physical and biological mechanisms will constrain behaviour during settlement. Apogonids will not be able to rely on current-dependent cues for far field orientation towards reefs. Current patterns around reefs are characterised by a high degree of variability (Sanderson et al. 1995). As physical constraints will now be binding, there is less scope for larval behaviour to filter this variability. Thus we would expect less consistent recruitment patterns for apogonids than for stronger-swimming species; the field data of Williams \& Sale (1981) support this conclusion. Furthermore, recruitment patterns for apogonids are likely to show a greater degree of correlation with stochastic environmental forcing mechanisms than those of stronger-swimming species.

Consideration should be given to alternative strategies by which apogonids and other weak-swimming species could overcome physical constraints on settlement success. One such strategy would be the acceptance of a broader range of habitats on initial settlement; this in turn leads to the possibility of tripartite life histories involving 2-phase settlement events (Finn $\&$ Kingsford 1996). Apogonid larvae might be expected to make greater use of advection avoidance mechanisms than stronger swimmers; these would include vertical migration and exploitation of the benthic boundary layer. Lastly, a reduced ability to reach reefs from open water could result in shorter pelagic larval durations; such a reduction would enhance the probability of being retained near to a reef (Black 1994). Swimming abilities decrease with decreasing pelagic larval duration (see Fig. 4b in Stobutzki \& Bellwood 1997), but the direction of any causality in this relationship may not be clear.

\section{CONCLUSION}

There has been a tendency when constructing models in ecology to opt for as detailed a set of assumptions as possible, and to study specific situations with large numerical simulations. This tendency is not always helpful, as it removes the possibility of finding generalities common to several situations, and can conceal simple causal relationships behind layers of correlated detail (Levin 1990). There is, then, a need to accompany the construction of large complicated models with simple theoretical constructs, and, where possi. ble, to indicate situations where the output of a simple model can be used in favour of a more detailed, but more cumbersome, counterpart (Murdoch \& Nisbet 1996). Two significant conclusions from the models that I have presented are that (1) there are generalisations that can be drawn regarding how the swimming of larvae towards reefs can affect the supply rates of larvae; and (2) certain detailed data sets, that would be expensive to collect, will not substantively change the stated results. 
The models illustrate that 4 possible scenarios need consideration, separating weak-and strong-swimming larvae, and separating larvae that orient towards current-dependent and -independent cues. In the 3 scenarios where the independent movement of larvae towards reefs proves to be a significant factor (cases 1 to 3 ) in determining the supply rate of larvae, the strength of the sensory faculty employed is the critical parameter. The models illustrate the sensitive dependence of the size of sensory zone and rates of larval supply upon this parameter. When considering weakswimming larvae that rely on current-dependent cues for orientation, larval swimming cannot enhance the supply rate of larvae to reefs, and active behaviour may be of limited significance.

The sensitive dependence on the strength of the sensory faculty employed to detect reefs means that small changes in these capabilities can result in large changes in supply rates. Therefore, determining the nature and discriminatory properties of the sensory faculties used by different species for orientation, and determining the detection power of these faculties, must become a fundamental research objective of those involved in management of reef fish populations.

Appendix 1. Current-independent cues

\section{Statement of trajectories}

As discussed in 'Methods: Current-independent cues',

$$
\begin{aligned}
& I(r, \theta)=\frac{I_{0}}{2 \pi r} \\
& \Rightarrow \frac{\partial I}{\partial \theta}=0 \\
& \Rightarrow \mathbf{n}=\frac{\mathbf{r}}{|\mathbf{r}|}
\end{aligned}
$$

where $\mathbf{n}$ is from Eq. (12). Then inside the sensory zone the equation of motion in polar form becomes

$$
\begin{aligned}
\dot{I} & =-v_{\mathrm{s}}+v_{\mathrm{a}} \cos \theta \\
r \dot{\theta} & =-v_{\mathrm{a}} \sin \theta
\end{aligned}
$$

The trajectories are given by

$$
\begin{aligned}
\frac{\mathrm{d} r}{\mathrm{~d} \theta} & =\frac{\left(v_{\mathrm{s}}-v_{\mathrm{a}} \cos \theta\right) r}{v_{\mathrm{a}} \sin \theta} \\
\Rightarrow \frac{\mathrm{d} r}{r} & =\frac{v_{\mathrm{s}}}{v_{\mathrm{a}}} \csc \theta \mathrm{d} \theta-\cot \theta \mathrm{d} \theta \\
\Rightarrow \quad r & =\frac{A|\csc \theta-\cot \theta|^{v_{\mathrm{s}} / v_{\mathrm{a}}}}{|\sin \theta|}
\end{aligned}
$$

where $A$ is some positive constant, as stated in Eq. (17).

\section{Separatrices}

We restrict our attention to weak swimmers for the remainder of Appendix 1. The separatrices are those members of the family of trajectories parameterised by $A$ that are tangential to the near-reef zone $R_{2}=r$. Therefore they must satisfy

$$
\frac{\mathrm{d} x}{\mathrm{~d} y}=-\frac{y}{x} \quad \text { when } \quad x^{2}+y^{2}=R_{2}^{2}
$$

Then, from the Cartesian statement of Eq. (16) inside the sensory zone,

$$
\begin{aligned}
& \dot{x}=v_{\mathrm{a}}-v_{\mathrm{s}} \frac{x}{\sqrt{x^{2}+y^{2}}} \\
& \dot{y}=-v_{\mathrm{s}} \frac{y}{\sqrt{x^{2}+y^{2}}}
\end{aligned}
$$

$$
\Rightarrow \frac{\mathrm{d} x}{\mathrm{~d} y}=\frac{-v_{\mathrm{a}} r+v_{\mathrm{s}} x}{v_{\mathrm{s}} y}
$$

Setting this equal to $-y / x_{1}$ when $r=R_{2}$ gives

$$
\begin{aligned}
& \quad-\frac{V_{\mathrm{a}} R_{2} x}{V_{\mathrm{s}}}+x^{2}+y^{2}=0 \\
& \Rightarrow \quad x=R_{2} \frac{V_{\mathrm{s}}}{V_{\mathrm{a}}} \\
& \text { and } y= \pm R_{2}\left(1-\frac{V_{\mathrm{s}}^{2}}{V_{\mathrm{a}}^{2}}\right)^{1 / 2}
\end{aligned}
$$

or in polar form

$$
\begin{aligned}
& r=R_{2} \\
& \theta=\arctan \pm\left(\frac{v_{\mathrm{a}}^{2}}{v_{\mathrm{s}}^{2}}-1\right)^{1 / 2}
\end{aligned}
$$

At this point we observe that for real values of $y$ we must have $v_{a}>v_{s}$. In other words the separatrices only exist for weak swimmers, and no division of the patch occurs if we are studying strong swimmers, all of which can reach the reef.

To find the separatrices explicitly, we input this point into Eq. (17). Firstly we seek the separatrix in the upper half plane, and hence take positive square roots and drop modulus signs. On substituting for $r$ and $\theta$ and re-arranging, we find

$$
\begin{aligned}
A & =R_{2} \frac{\left[1-\left(\frac{V_{\mathrm{s}}}{V_{\mathrm{a}}}\right)^{2}\right]^{\left(1+y_{\mathrm{s}} / v_{\mathrm{a}} / / 2\right.}}{\left(1-\frac{V_{\mathrm{s}}}{V_{\mathrm{a}}}\right)^{v_{\mathrm{s}} / v_{\mathrm{a}}}} \\
& =R_{2}\left(1-\frac{V_{\mathrm{s}}}{V_{\mathrm{a}}}\right)^{\left(1-V_{\mathrm{s}} / v_{\mathrm{a}} / / 2\right.}\left(1+\frac{V_{\mathrm{s}}}{V_{\mathrm{a}}}\right)^{\left(1+v_{\mathrm{s}} / v_{\mathrm{a}}\right) / 2}
\end{aligned}
$$

The other separatrix is found similarly.

With the explicit statements for the separatrices, we can derive equations for $\theta=\breve{\theta}$ at the intersection points of each separatrix with the boundary of $S_{c}$ given by $r=\frac{I_{0}}{2 \pi c}$. The effective target size is then found to be $\frac{I_{0}}{\pi c} \sin \check{\theta}$ 
Appendix 2. Current-dependent cues

The solution of Eq. (4) corresponding to a point release of tracer from $\left(x^{\prime}, y^{\prime}\right)$ into a stationary medium at time $t^{\prime}$ is

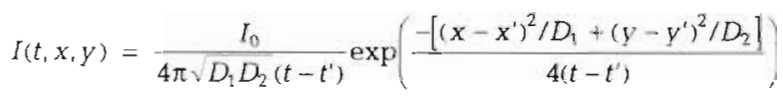

Now suppose this signal was released into a constant current (Eq. 8) from the origin, then the effects of that release will be focused around $\left[v_{a}\left(t-t^{\prime}\right), 0\right]$ at time $t$. So our instantaneous point release solution becomes

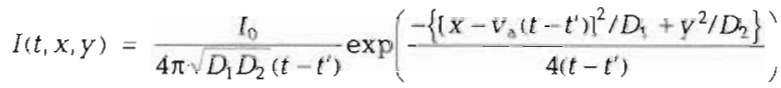

As Eq. (4) is linear in highest order terms, the principle of superposition guarantees that an integral sum of solutions is also a solution. We construct a continuous release as the integral sum of instantaneous point releases to obtain the solution,

$$
\begin{aligned}
& I(t, x, y)=\int_{0}^{t} \frac{I_{0}}{4 \pi \sqrt{D_{1} D_{2}\left(t-t^{\prime}\right)}} \exp \left(\frac{-\left\{\left[x-v_{s}\left(t-t^{\prime}\right)\right]^{2} / D_{1}+y^{2} / D_{2}\right\}}{4\left(t-t^{\prime}\right)}\right) \mathrm{d} t^{\prime} \\
& =\frac{I_{0}}{4 \pi \sqrt{D_{1} D_{2}}} \mathrm{e}^{v_{0} x /\left(2 D_{1}\right)} \int_{0}^{t} \exp \left[\frac{-\left(x^{2} / D_{1}+y^{2} / D_{2}\right)}{4\left(t-t^{\prime}\right)}-\frac{v_{d}^{2}\left(t-t^{\prime}\right)}{4 D_{1}}\right] /\left(t-t^{\prime}\right) \mathrm{d} t^{\prime}
\end{aligned}
$$

Making the substitution

$$
\begin{aligned}
& \xi=\left[\frac{x^{2} / D_{1}+y^{2} / D_{2}}{4\left(t-t^{\prime}\right)}\right]^{1 / 2} \\
\Rightarrow & 2 \frac{\mathrm{d} \xi}{\xi}=\frac{\mathrm{d} t^{\prime}}{\left(t-t^{\prime}\right)}
\end{aligned}
$$

we obtain

$$
I=\frac{I_{0}}{2 \pi \sqrt{D_{1} D_{2}}} \mathrm{e}^{v_{\mathrm{a}} \times\left(2 D_{1}\right)} \int_{q / 2 t^{1 / 2}}^{\infty} \frac{1}{\xi} \exp \left(-\xi^{2}-\frac{v_{\mathrm{a}}^{2} q^{2}}{16 D_{1} \xi^{2}}\right) \mathrm{d} \xi
$$

where $q=\left(x^{2} / D_{1}+y^{2} / D_{2}\right)^{1 / 2}$. The integral

$$
\int_{0}^{\infty} \frac{1}{z} \exp \left[-\left(z^{2}+\frac{b^{2}}{z^{2}}\right)\right] \mathrm{d} z=K_{0}(2 b) \text { for real } b
$$

can either be found from tables or derived from first principles by contour integration. Therefore taking the limit of $I$ as $t \rightarrow \infty$, we obtain the steady-state approximation (Eq. 22),

$$
I(x, y)=\frac{I_{0}}{2 \pi \sqrt{D_{1} D_{2}}} e^{v_{1} x^{\prime}\left(2 D_{1}\right)} K_{0}\left(\frac{V_{\mathrm{a}} q}{2 \sqrt{D_{1}}}\right)
$$

Some caution is needed when working with $I$ in any numerical schemes, because the contribution from the exponential term can become very large, while the contribution from the Bessel function can become very small; introducing a factor of $\exp \left[v_{\mathrm{a}} q /\left(2 \sqrt{D_{1}}\right)\right]$ avoids these difficulties.

Now we derive $\frac{\partial I}{\partial x}$ and $\frac{\partial I}{\partial y}$ to input into Eq. (23). We require the property of the modified Bessel functions that

$$
\frac{\mathrm{d}}{\mathrm{d} z} K_{0}(z)=-K_{1}(z)
$$

where $K_{1}$ is the modified Bessel function of first order (details given in Arfken 1985). Then applications of the product rule and chain rule give Eq. (24),

$$
\begin{aligned}
& \frac{\partial I}{\partial x}=\frac{I_{0} v_{\mathrm{a}}}{4 \pi D_{1}^{3 / 2} D_{2}^{1 / 2}} \exp \left(\frac{v_{\mathrm{a}} X}{2 D_{1}}\right)\left[K_{0}\left(\frac{v_{\mathrm{a}} q}{2 D_{1}^{1 / 2}}\right)-\frac{x}{q D_{1}^{1 / 2}} K_{1}\left(\frac{v_{a} q}{2 D_{1}^{1 / 2}}\right)\right] \\
& \text { and } \\
& \frac{\partial I}{\partial y}=-\frac{I_{0} V_{a} y}{4 \pi D_{1} D_{2}^{3 / 2}} \exp \left(\frac{v_{\mathrm{a}} x}{2 D_{1}}\right) K_{1}\left(\frac{v_{\mathrm{a}} q}{2 D_{1}^{1 / 2}}\right)
\end{aligned}
$$

Acknowledgements. I would like to thank Lance Bode, Maurice James, David Bellwood and 4 anonymous referees for their helpful comments on the manuscript; Lance Bode for his assistance with the preparation of the figures; and David Bellwood for his suggestions regarding the interpretation of model findings. This work was generously supported by the Northcote Trust.

\section{LITERATURE CITED}

Arfken G (1985) Mathematical methods for physicists. Academic Press, London

Armsworth PR, Bode L (1999) The consequences of non-passive advection and directed motion for population dynamics. Proc R Soc Lond Ser A 455:4045-4060

Arvedlund M, Nielsen LE (1996) Do the anemonefish Amphiprion ocellaris (Pisces: Pomacentridae) imprint themselves to their host sea anemone Heteractis magnifica (Anthozoa: Actinidae). Ethology 102:197-211

Bellwood DR, Leis JM, Stobutzki IC (1998) Fishery and reef management. Science 279:2021-2022

Black KP (1993) The relative importance of local retention and inter-reef dispersal of neutrally buoyant material on coral reefs. Coral Reefs 12:43-53
Black KP (1994) Developments in our knowledge of dispersal on the Great Barrier Reef. In: Sammarco PW. Heron ML (eds) The bio-physics of larval dispersal. American Geophysical Union, Washington, p 159-192

Carslaw HS, Jaeger JC (1947) Conduction of heat in solids. Clarendon Press, Oxford

Crank J (1975) The mathematics of diffusion. Clarendon Press, Oxford

Dayton PK, Thrush SF, Agardy MT, Hofman RJ (1995) Environmental effects of marine fishing. Aquat Conserv 5:205-232

Dight IJ, Black KP (1991) Numerical simulation of larval dispersal and recruitment to coral reefs from the mainstream water circulation. Proc 7 th Symp Coastal Ocean Management 3:1995-2009

Dight IJ, James MK, Bode L (1990a) Modelling the larval dispersal of Acanthaster planci I: large scale hydrodynamics, Cairns Section, Great Barrier Reef Marine Park. Coral Reefs 9:115-123

Dight IJ, James MK, Bode L (1990b) Modelling the larval dispersal of Acanthaster planci II: patterns of reef connectivity. Coral Reefs 9:125-134

Dittman AH, Quinn TP (1996) Homing in Pacific salmon: mechanisms and ecological basis. J Exp Biol 199:83-91

Doherty PJ, Fowler T (1994) An empirical test of recruitment limitation in a coral reef fish. Science 263:935-939 
Doherty $\mathrm{P}, \mathrm{Mcllwain} \mathrm{J}(1996)$ Monitoring larval fluxes through the surf zones of Australian coral reefs. Aust J Mar Freshw Res 47:383-390

Doherty PJ, Williams DMcB (1988) The replenishment of coral reef fish populations. Oceanogr Mar Biol Annu Rev 26: $487-551$

Doherty P, Kingsford M, Booth D, Carleton J (1996) Habitat selection before settlement by Pomacentrus codestis. Aust J Mar Freshw Res 47:391-399

Done T, Bode L, Coles R, Crossland C, Engelhardt U, Furnas $M$, Woolfe K (1997) Issue driven research for managing the Great Barrier Reef: progress and future directions. Proc GBR Science Use Management. GBRMPA, Townsville 1: $141-150$

Dufour V, Galzin R (1993) Colonization patterns of reef fish larvae to the lagoon at Moorea Island, French Polynesia. Mar Ecol Prog Ser 102:143-152

Elliott JK, Elliott JM, Mariscal RN (1995) Host selection, location and association behaviors of anemonefishes in field settlement experiments. Mar Biol 122:377-389

Finn MD, Kingsford MJ (1996) Two-phase recruitment of a coral reef fish (Pisces: Apogonidae) on the Great Barrier Reef. Aust J Mar Freshw Res 47:423-432

Foreman MGG, Baptista AM, Walters RA (1992) Tidal model studies of particle trajectories around a shallow bank. Atmos-Ocean 30:43-69

Frith CA, Leis JM, Goldman B (1986) Currents in the Lizard Island region of the Great Barrier Reef Lagoon and their relevance to potential movements of larvae. Coral Reefs 5: $81-92$

James MK, Dight IJ, Day JC (1990) Application of larval dispersal models to zoning of the Great Barrier Reef Marine Park. Proc PACON 1990. PACON, Tokyo 2:140-145

James MK, Mason LB, Bode L (1997) Larval transport modelling in the Great Barrier Reef. Proc GBR Science Use Management. GBRMPA, Townsville 2:361-375

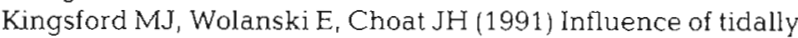
induced fronts and Langmuir circulations on distribution and movements of presettlement fish. Mar Biol 109:167-180

Kundu PK (1990) Fluid mechanics. Academic Press, San Diego Leis JM (1991) The pelagic stage of reef fishes: the larval biology of coral reef fishes. In: Sale PF (ed) The ecology of fishes on coral reefs. Academic Press, London, p 183-230

Leis JM, Carson-Ewart B (1997) In situ swimming speeds of the late pelagic larvae of some Indo-Pacific coral-reef fishes. Mar Ecol Prog Ser 159:165-174

Leis JM, Carson-Ewart B (1998) Complex behaviour by coralreef fish larvae in open-water and near-reef pelagic environments. Environ Biol Fishes 53:259-266

Leis JM, Sweatman HPA, Reader SE (1996) What the pelagic stages of coral reef fishes are doing out in blue water: daytime field observations of larval behavioural capabilities. Aust J Mar Freshw Res 47:401-411

Levin SA (1990) Ecology in theory and application. In: Levin SA, Hallam TG, Gross LJ (eds) Applied mathematical ecology. Springer-Verlag, Berlin, p 3-8

McCauley RD (1997) Aspects of marine biological sound in Northern Australia IV: fish choruses in the Great Barrier Reef: spatial extent and temporal patterns. Report to the Defence Science and Technology Organisation, Pyrmont, NSW

McCauley RD. Cato DH (1998) Evening fish choruses near coral reef systems in the Great Barrier Reef, Australia.

Editorial responsibility: Otto Kinne (Editor),

Oldendorf/Luhe, Germany
Proc 16th Int Congr Acoustics. Acoustical Society of America, Seattle, p 1029-1030

McCormick MI (1998) Condition and growth of reef fish at settlement: is it important? Aust J Ecol 23:258-264

McCormick MI (1999) Delayed metamorphosis of a tropical reef fish (Acanthurus triostegus): a field experiment. Mar Ecol Prog Ser 176:25-38

Murdoch WW, Nisbet RM (1996) Frontiers of population ecology. In: Floyd RB, Sheppard AW, De Barro PJ (eds) Frontiers of population ecology. CSIRO Publishing, Collingwood, p 31-43

Okubo A (1980) Diffusion and ecological problems: mathematical models. Springer-Verlag, Berlin

Ridderinkhof $\mathrm{H}$, Zimmerman JTF (1992) Chaotic stirring in a tidal system. Science 258:1107-1111

Russ GR (1991) Coral reef fisheries: effects and yields. In: Sale PF (ed) The ecology of fishes on coral reefs. Academic Press, London, p 601-635

Sancho G, Ma D, Lobel PS (1997) Behavioural observations of an upcurrent reef colonization event by larval surgeonfish Ctenochaetus strigosus (Acanthuridae). Mar Ecol Prog Ser 153:311-315

Sanderson BG, Okubo A, Webster IT, Kioroglou S, Appeldoorn R (1995) Observations and idealised models of dispersion on the Southwestern Puerto Rican Insular Shelf. Math Comp Model 21:39-63

Stobutzki IC (1997) Energetic cost of sustained swimming in the late pelagic stages of reef fishes. Mar Ecol Prog Ser 152:249-259

Stobutzki IC, Bellwood DR (1994) An analysis of the sustained swimming abilities of pre- and post-settlement coral reef fishes. J Exp Mar Biol Ecol 175:275-286

Stobutzki IC, Bellwood DR (1997) Sustained swimming abilities of the late pelagic stages of coral reef fishes. Mar Ecol Prog Ser 149:35-41

Stobutzki IC, Bellwood DR (1998) Nocturnal orientation to reefs by late pelagic stage coral reef fishes. Coral Reefs 17: $103-110$

Sweatman H (1988) Field evidence that settling coral reef fish larvae detect resident fishes using dissolved chemical cues. J Exp Mar Biol Ecol 124:163-174

Wehner R (1997) Sensory systems and behaviour. In: Krebs JR, Davies NB (eds) Behavioural ecology: an evolutionary approach. Blackwell Science, Oxford, p 19-41

Werner FE, Paye FH, Lynch DR, Loder JW, Lough RG, Perry RI, Greenberg DA, Sinclair MM (1993) Influences of mean advection and simple behaviour on the distribution of cod and haddock early life stages on Georges Bank. Fish Oceanogr 2:43-64

Williams DMcB, Sale PF (1981) Spatial and temporal patterns of recruitment of juvenile coral reef fishes to corai habitats within 'One Tree Lagoon', Great Barrier Reef. Mar Biol 65: 245-253

Wolanski E, Hamner WH (1988) Topographically controlled fronts in the ocean and their biological influence. Science 241:177-181

Wolanski E, Sarsenski J (1997) Larvae dispersion in coral reefs and mangroves. Am Sci 85:236-243

Wolanski E, Doherty P, Carleton J (1997) Directional swimming of fish larvae determines connectivity of fish populations on the Great Barrier Reef. Naturwissenschaften 84 : $262-268$

Submitted: June 24, 1999; Accepted: September 15, 1999

Proofs received from author(s): March 7, 2000 